\title{
Electronic Implants: Power Delivery and Management
}

\author{
Jacopo Olivo, Sara S. Ghoreishizadeh, Sandro Carrara, and Giovanni De Micheli \\ Integrated Systems Laboratory - EPFL \\ Lausanne, Switzerland \\ email: jacopo.olivo@epfl.ch
}

\begin{abstract}
A power delivery system for implantable biosensors is presented. The system, embedded into a skin patch and located directly over the implantation area, is able to transfer up to $15 \mathrm{~mW}$ wirelessly through the body tissues by means of an inductive link. The inductive link is also used to achieve bidirectional data communication with the implanted device. Downlink communication (ASK) is performed at $100 \mathrm{kbps}$; uplink communication (LSK) is performed at $66.6 \mathrm{kbps}$. The received power is managed by an integrated system including a voltage rectifier, an amplitude demodulator and a load modulator. The power management system is presented and evaluated by means of simulations.
\end{abstract}

Index Terms-Remote powering, inductive link, energy harvesting, implantable biosensors, lactate measurement.

\section{INTRODUCTION}

The research field of implantable biosensors has attracted the interest of academia and industry in the last two decades. The possibility of continuous monitoring of the human body from inside is an opportunity to better understand the ways the body works and paves the way to a large number of applications.

As an example, the continuous monitoring of the glucose level in the subcutaneous interstitial fluids is an important aid to those patients who suffer from diabetes. By using implantable sensors located in the subcutaneous zones, the percentage of glucose in the blood (glycemia) can be recorded and analyzed [1]. Thus, periodic and disturbing blood sampling can be avoided. Lactate can also be monitored by means of subcutaneous sensors [2]. The lactate concentration in the blood (lactatemia) or interstitial tissues in muscle can be recorded to monitor the muscular effort in sportsmen or people under rehabilitation. Finally, many other human metabolites can be detected with subcutaneous biosensors [3].

Several key challenges must be addressed to realize these scenarios [4]: implantable biosensors should be minimally invasive, completely biocompatible, highly reliable, and with a low thermal dissipation. Security and privacy should be provided during data transmission. Finally, large power autonomy should be ensured. This last requirement must be carefully

The research work presented was funded by the i-IronIC project and by the NanoSys project. The NanoSys project is within the program ERC-2009-AdG246810 , the i-IronIC project was financed with a grant from the Swiss NanoTera.ch initiative and evaluated by the Swiss National Science Foundation.

978-3-9815370-0-0/DATE13/(C)2013 EDAA considered, since the performance and the invasivity of an implantable sensor strongly depend by the battery size and the battery lifetime.

Modern batteries have increased capabilities with respect to those available in the past. As an example, lithium-ion batteries have reached a high level of energy density (up to $0.2 \mathrm{Wh} / \mathrm{g}$ ) and can maintain an almost constant voltage until they are discharged to $75 \%-80 \%$ [5]. Furthermore, thinfilm rechargeable batteries can sensibly reduce the size of battery-powered devices [6]. However, even with an improved energy density, batteries still represent a bottleneck in the miniaturization of implantable sensors. Moreover, substituting the battery can cause discomfort to the patient.

Energy harvesting techniques exploit natural and/or artificial power sources surrounding the person to assist the implanted batteries, to recharge them and in certain cases replace them. A review of the most popular harvesting techniques for implantable sensor can be found in [7].

Remote powering through inductive link is a well known method of delivering power to an implanted device. In such a technique, a current flowing through an external inductor (transmitter) induces a current through one or more implanted inductors (receiver); thus, power is transmitted wirelessly through the body tissues. Several solutions have been proposed in the literature [8-17]. Commercial devices exploiting inductive links for the remote powering of implantable systems already reached the market [18]. However, the wearability of the power transmitter (delivery module) and the miniaturization of the implanted receiver (delivery and management modules) is still an open research topic.

Inductive links are also used to perform bidirectional data communication with the implanted devices $[8,12,13,15]$. Downlink communication (from the external transmitter to the implanted device) can be obtained by modulating the power carrier generated by the transmitter. Uplink communication (from the implanted device to the external transmitter) can be obtained by modulating the load of the receiving inductor; this modulation is detected as a change of current flowing through the external inductor. Thus, no implanted RF transmitter is needed.

The focus of this paper is on the power delivery and power management. A target device for metabolite measurement is reported in Section II. Section III describes the system 


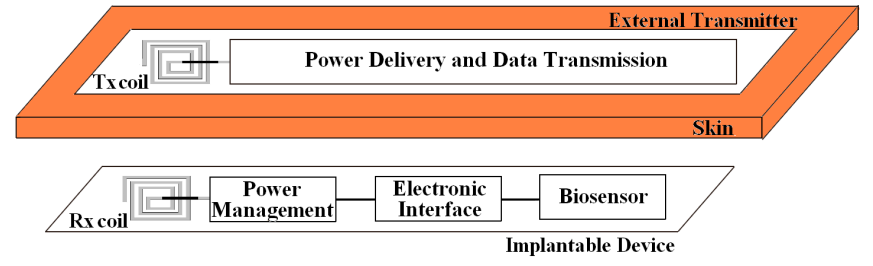

Fig. 1. Schematic view of the implantable system and the power delivery module.

designed to remotely power the target device. The electronics to manage the received power and to efficiently store it is presented in Section IV. Finally, Section V concludes the paper.

\section{TARget Device}

\section{A. System Description}

In this section a metabolite sensor and the integrated circuit to perform metabolite measurements are presented. A diagram of the system is shown in Fig. 1. The main blocks of the implantable device are the biosensor, the electronic interface, the power management module, and the receiving inductor.

The biosensor consists of an electrochemical cell with three electrodes (Fig. 2). In order to measure the metabolite concentration, a fixed voltage $\mathrm{V}_{\text {ox }}$ (oxidation potential) is applied between working electrode (WE) and reference electrode (RE). As a result, a current flows between the working electrode and the counter electrode (CE) due to the metabolite oxidation. To increase the biosensor selectivity to a specific target, different enzymes can be immobilized on the surface of the working electrode [19].

A main issue of metabolite biosensors is the lack of stability. Moreover, the sensor parameters are strongly affected by the immobilization method of the enzyme onto the electrode. Previous works have investigated the use of multi-walled carbon nanotubes (MWCNTs) to immobilize the enzyme onto the electrodes [20,21]. The enhanced adhesion, due to MWCNTs, improves the performance of the sensor [20].

\section{B. Circuit Design}

An electronic interface (EI) is designed to perform electrochemical measurements of lactate with the three-electrode configuration of Fig. 2. The EI, reported in Fig. 3, includes the potentiostat, the readout circuit, the reference voltage generators and the ADC.

The potentiostat consists of OPAMPs $\mathrm{OP}_{1}$ and $\mathrm{OP}_{2}$, together with transistors $\mathrm{MP}_{0}$ and $\mathrm{MP}_{2}$. It applies a fixed voltage of $650 \mathrm{mV}$ (oxidation potential of several metabolites, including glucose and lactate) between WE and RE.

The readout circuit consists of current mirrors and a resistor to generate a copy of the cell current $\mathrm{I}_{\mathrm{WE}}$. The copied current is then converted into a voltage and measured, while providing isolation for the sensor current $\mathrm{I}_{\mathrm{WE}}$. The potentiostat and the readout circuit are fabricated in $0.18 \mu \mathrm{m}$ CMOS technology and consume $45 \mu \mathrm{A}$ with a supply voltage of $1.8 \mathrm{~V}$.

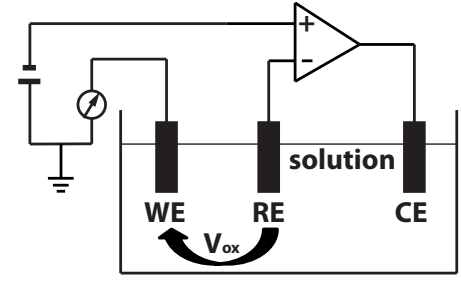

Fig. 2. Three-electrode electrochemical cell and measurement set-up.

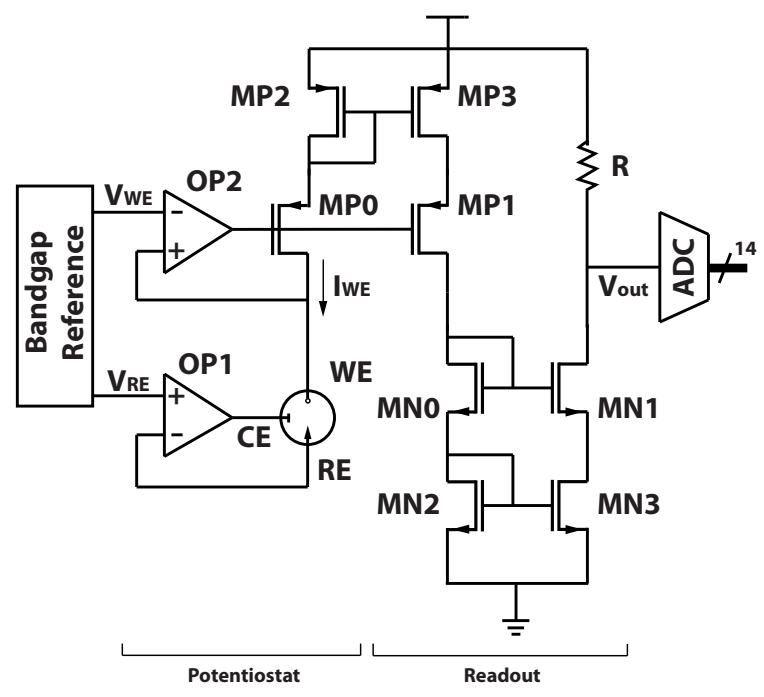

Fig. 3. Electronic interface for metabolite measurement.

Two bandgap reference circuits are designed to generate a voltage of $650 \mathrm{mV}$ between $\mathrm{WE}$ and RE. That voltage is independent from temperature and supply. A voltage of $550 \mathrm{mV}$ is applied to the RE by means of a sub-1V bandgap reference [22]; a voltage of $1.2 \mathrm{~V}$ is applied to the WE by means of a regular bandgap reference. Thus, $650 \mathrm{mV}$ are measured between WE and RE.

An ADC is designed to digitize the output voltage of the readout circuit. The current range and the sensitivity of the biosensor depends on the geometry of the electrodes and the enzyme used [3,21]. In this work, the maximum value of $\mathrm{I}_{\mathrm{WE}}$ is set to $4 \mu \mathrm{A}$ and the current resolution is set to $250 \mathrm{pA}$, in order to be compliant with a wide range of sensors with different geometries and enzymes. To digitize $4 \mu \mathrm{A}$ with the resolution of $250 \mathrm{pA}$, a 14-bit $\mathrm{ADC}$ is required. The designed $\mathrm{ADC}$ is a second order sigma-delta, implemented in $0.18 \mu \mathrm{m}$ CMOS technology. The area of the ADC and the bandgap reference is $0.3 \mathrm{~mm}^{2}$. The simulated current consumption is $240 \mu \mathrm{A}$ with a supply voltage of $1.8 \mathrm{~V}$.

\section{Measurement Results}

The potentiostat and the readout circuit in Fig. 3 are used to measure lactate concentration. Two different enzymes are immobilized on the screen printed electrodes: commercial (cLODx) and wild type (wtLODx). MWCNTs are used to enhance the performance of the sensor. The measured char- 


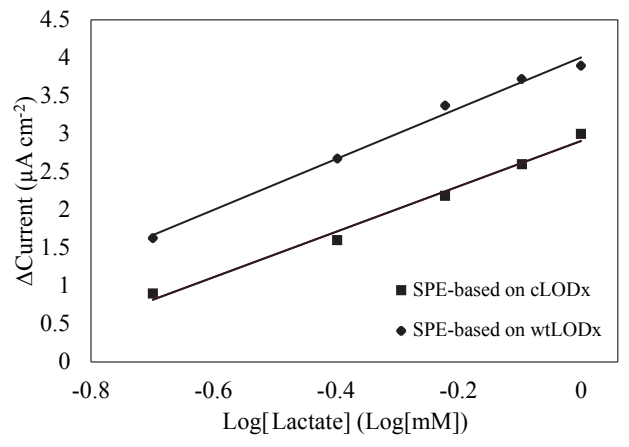

Fig. 4. Lactate measurement using the potentiostat and the readout circuit reported in Fig. 3.

acteristic is shown in Fig. 4. The results are in agreement with those obtained with a commercial potentiostat. A detailed discussion can be found in [23].

\section{POWER Delivery}

In this section is described the device to deliver power to the target sensor presented in Section II. Further details can be found in [24]. The system, named IronIC patch, is designed to be embedded into a skin patch and placed directly over the implantation zones. Designed on a flexible substrate, the device can be used on concave or convex parts of the body (Fig. 5).

\section{A. System Description}

A schematic description of the patch is given in Fig. 6, from [24]. Power is transmitted to the implanted system by driving the transmitting inductor with a class-E power amplifier. Amplifiers in class-E are commonly used to drive inductive links due to the high efficiency, theoretically equal to $100 \%$ [25-27]. Indeed, by properly tuning the amplifier capacitors $\mathrm{C}_{3}$ and $\mathrm{C}_{4}$, the current and the voltage across the switch $\mathrm{M}_{2}$ are never non-zero at the same time. In this design, the amplifier is driven by a $5 \mathrm{MHz}$ square waveform with duty cycle $50 \%$.

Downlink communication is achieved by modulating the amplitude of the current flowing on the transmitting inductor $\mathrm{L}_{2}$. Amplitude modulation (Amplitude Shift Keying - ASK) is a common approach when no high data-rates are required. Indeed, it noticeably simplifies the design of the embedded demodulator. The modulating signal is a bitstream generated by the microcontroller. The bit-rate is set to $100 \mathrm{kbps}$. Modulation depth is determined by the ratio between resistors $R_{7}$ and $\mathrm{R}_{8}$.

Uplink communication is achieved by modulating the load of the receiving inductor and detecting that modulation on the supply current of the class-E amplifier (Load Shift Keying LSK). To demodulate an uplink bitstream, the voltage drop across $R_{9}$ is digitized and analyzed by the microcontroller. A high voltage drop, due to a high current, is detected when the receiving inductor is not short-circuited; a low voltage drop, due to a low current, is detected when the receiving inductor

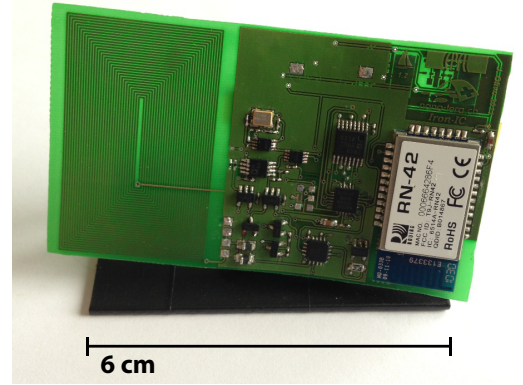

Fig. 5. The IronIC patch can be placed over the implantation zones, in concave or convex parts of the body, to power implanted sensors and communicate with them.

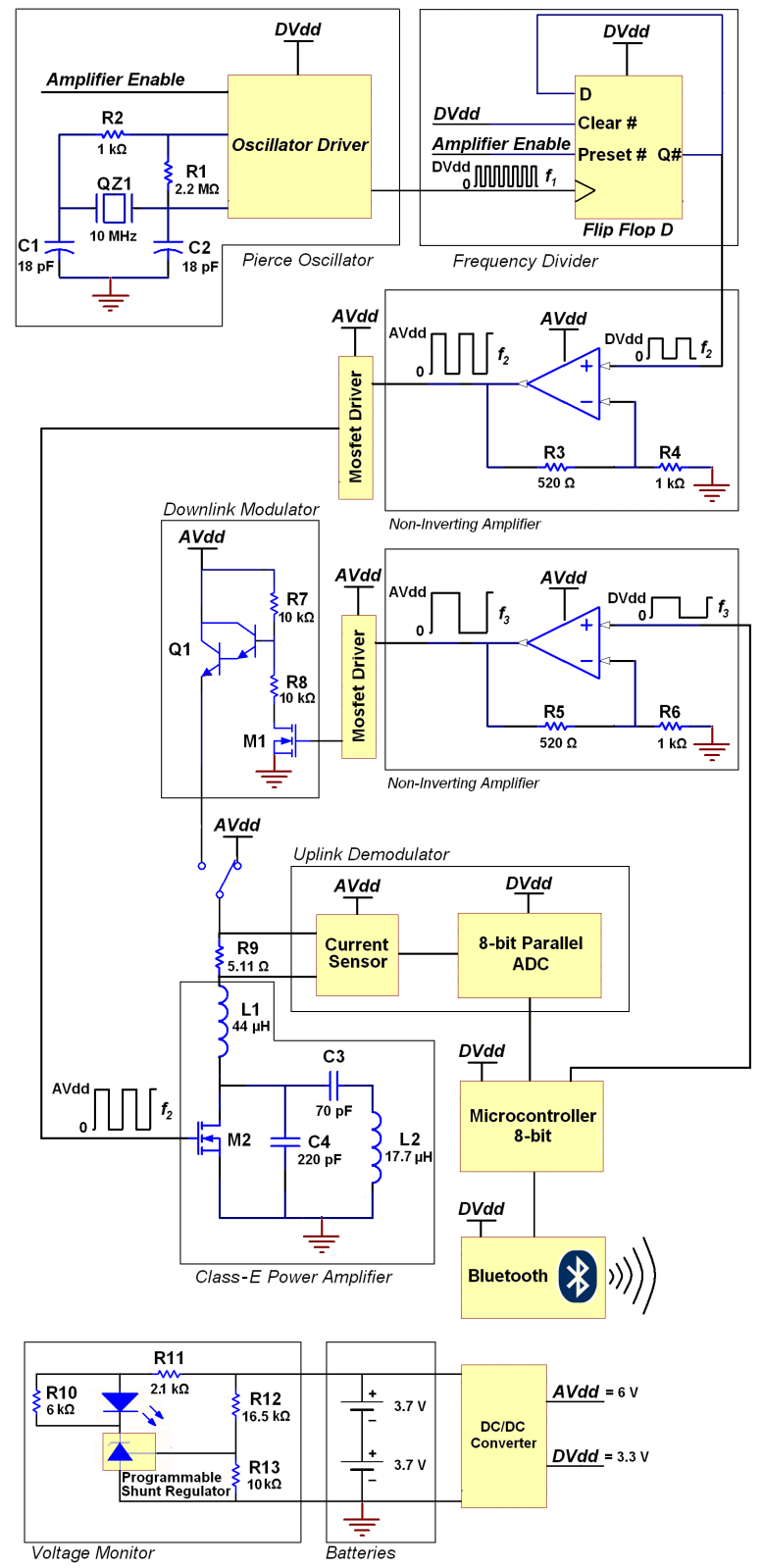

Fig. 6. Schematic of the IronIC patch at component level. Reprinted from [24]. 


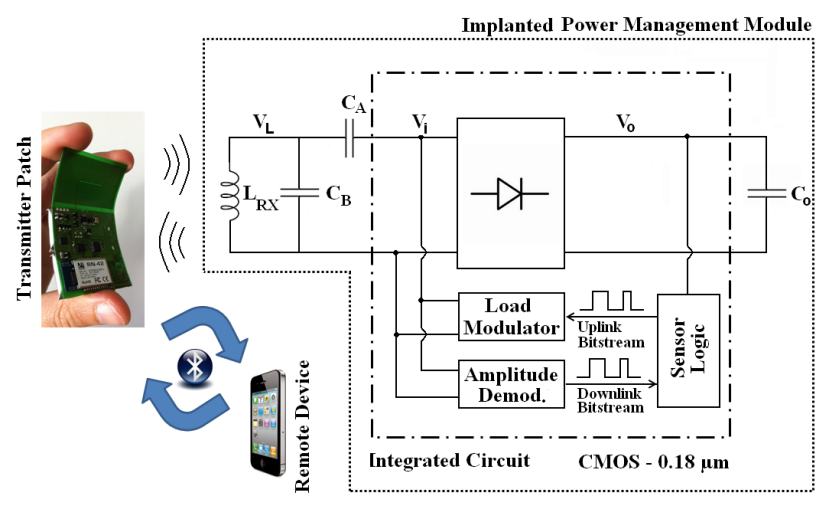

Fig. 7. The implanted sensor receives power and data from the external device (transmitter patch). The transmitter performs long-range communication with remote devices by means of bluetooth.

is short-circuited. Uplink bit-rate is set to $66.6 \mathrm{kbps}$. This value is slightly lower than the downlink bit-rate due to the computational time required to perform a real-time threshold check between high and low current values.

The whole system (amplifier, modulator, and demodulator) can be driven by a remote device, such as a laptop or a smartphone, by means of bluetooth connection. Moreover, acquired data are transmitted to the user by means of the bluetooth link.

\section{B. System Performance}

The system described is tested in air by using an 8-layer, 14-turn receiving inductor, having volume $38 \times 2 \times 0.544 \mathrm{~mm}^{3}$ [24]. Further details on the fabrication of the receiving inductor can be found in [28].

The received power, within a distance of $6 \mathrm{~mm}$ between the inductors, is $15 \mathrm{~mW}$. This value corresponds to the maximum transmitted power. The transmitted power can be decreased by properly tuning the class-E amplifier if a lower value is required by the implantable sensor. Measurements have been performed by using a beef sirloin between the inductors to emulate the presence of biological tissues. While a $17 \mathrm{~mm}$ thick slice of sirloin is placed between the coils, the transferred power is $1.17 \mathrm{~mW}$. This value is similar to that obtained in air, where the distance between the coils is set to $17 \mathrm{~mm}$.

While the patch is disconnected by the bluetooth and it is not sending power, the estimated battery duration is about $10 \mathrm{~h}$. This value decreases when the system is connected to a remote device, such as a laptop or a smartphone. In that case, the estimated battery duration is about $3.5 \mathrm{~h}$. While disconnected from the bluetooth, the patch can send power continuously for $1.5 \mathrm{~h}$.

\section{Power Management}

In order to use the power delivered by the receiving inductor, the implantable sensor must be equipped with a voltage rectifier and a low-dropout regulator. Moreover, an amplitude demodulator and a load modulator are needed to enable the downlink and the uplink communications, respectively. These circuits (rectifier, regulator, amplitude demodulator, and load

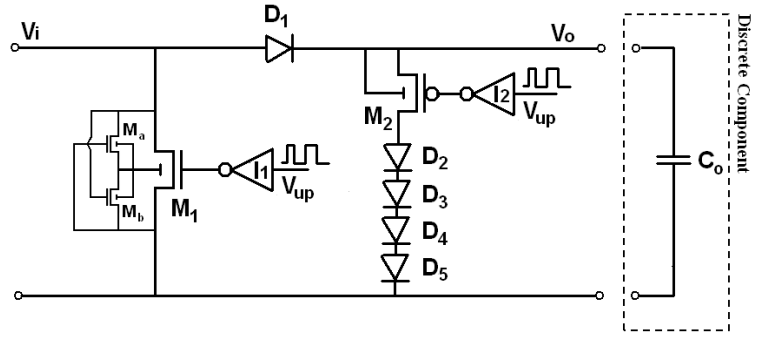

Fig. 8. Schematic of the voltage rectifier and the load modulation unit.

modulator) should be integrated within the sensor to provide a stable supply voltage and perform bidirectional, short-range communication.

In this section we describe the design of a power management module including voltage rectifier, ASK demodulator and LSK modulator. The module is designed in $0.18 \mu \mathrm{m}$ CMOS technology. A schematic view of the power management module is shown in Fig. 7.

\section{A. Voltage Rectifier and Load Modulator}

The schematic of the voltage rectifier is reported in Fig. 8, together with the load modulation unit. At the beginning of the operations, when no power is transmitted and the output capacitor is discharged, switch $\mathrm{M}_{1}$ is open and switch $\mathrm{M}_{2}$ is closed. Thus, the equivalent circuit is an half-wave rectifier with four clamping diodes to prevent overvoltage of the output $\left(\mathrm{V}_{\mathrm{o}} \leq 3 \mathrm{~V}\right)$. That configuration remains unchanged when capacitor $\mathrm{C}_{\mathrm{o}}$ is charged and a stable supply voltage is provided on-chip.

Load modulation is performed by switching the transistor $\mathrm{M}_{1}$ at the input of the rectifier according to the uplink

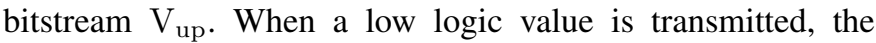
switch $M_{1}$ is closed and short-circuits the input of the rectifier; thus, no power is delivered to the load. To avoid the discharge of $\mathrm{C}_{\mathrm{o}}$ due to the leakage current of the clamping diodes, switch $\mathrm{M}_{2}$ is kept open when a low logic value is transmitted.

To prevent the latch-up of $\mathrm{M}_{1}$ when the input voltage $\mathrm{V}_{\mathrm{i}}$ has negative values, its bulk is not connected to ground. Transistor $M_{a}$ and $M_{b}$ are used to bias the bulk of $M_{1}$ to the lowest between drain and source voltages. To realize such circuit, the bulks of $\mathrm{M}_{1}, \mathrm{M}_{\mathrm{a}}$, and $\mathrm{M}_{\mathrm{b}}$ are fabricated within a separate n-well (triple well).

\section{B. Amplitude Demodulator}

As previously said, the power management module is equipped with an embedded ASK demodulator to read downlink bitstreams transmitted by the external patch. The schematic of the demodulator is reported in Fig. 9.

The circuit is driven by a two-phase non-overlapping clock signal $\left(\varphi_{1}\right.$ and $\varphi_{2}$, in Fig. 9). While signal $\varphi_{1}$ is high, the equivalent circuit is the one reported in Fig. 10a. Capacitor $\mathrm{C}_{2}$ is charged to the amplitude of the sinusoidal signal $\mathrm{V}_{\mathrm{i}}$ through the switch $\mathrm{M}_{10}$. Diodes $\mathrm{D}_{6}, \mathrm{D}_{7}$ and $\mathrm{D}_{8}$ prevent the discharge. The voltage across $\mathrm{C}_{2}$ is read as a logic value by inverters $\mathrm{I}_{3}$ and $\mathrm{I}_{4}$. During this phase, capacitor $\mathrm{C}_{1}$ is discharged. 


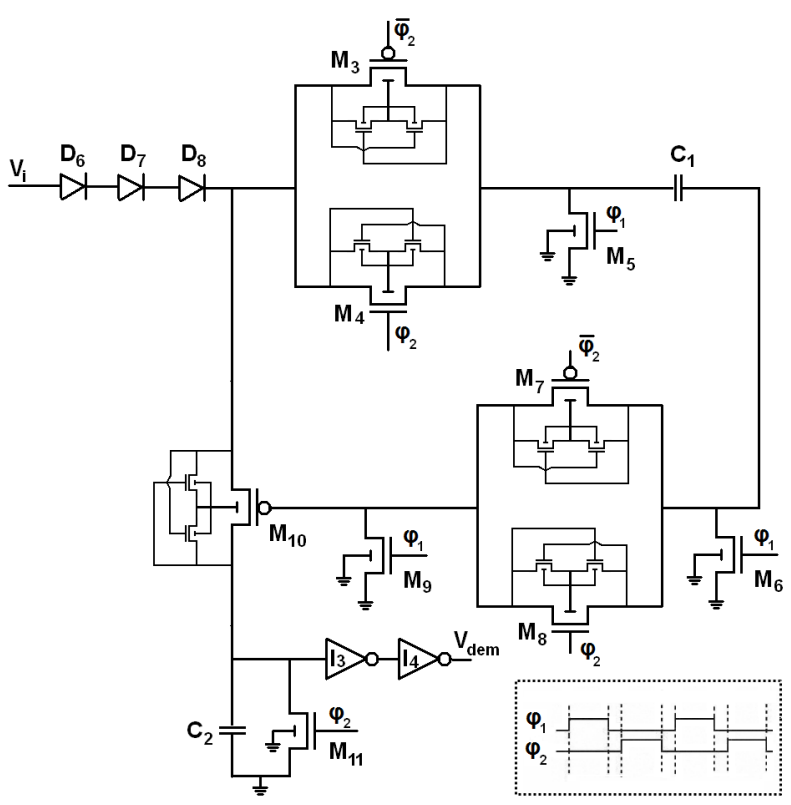

Fig. 9. Schematic of the amplitude demodulator. The circuit is driven by a two-phase non overlapping clock signal $\left(\varphi_{1}\right.$ and $\left.\varphi_{2}\right)$.

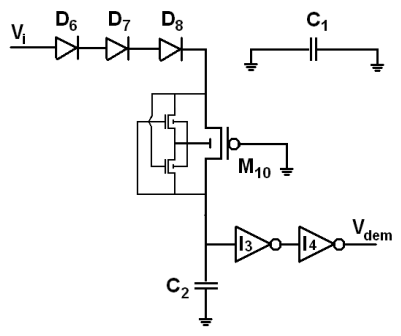

(a) $\varphi_{1}=1 ; \varphi_{2}=0$

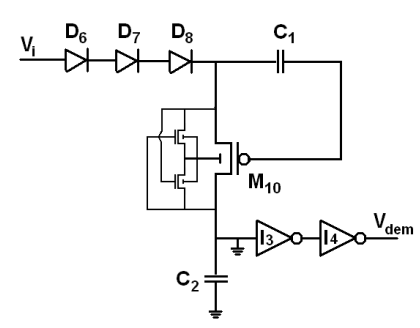

(b) $\varphi_{1}=0 ; \varphi_{2}=1$
Fig. 10. Equivalent circuit of the demodulator in Fig. 9 while $\varphi_{1}=1$ (a) and $\varphi_{2}=1(\mathrm{~b})$.

When signal $\varphi_{2}$ is high, the equivalent circuit is the one reported in Fig. 10b. Capacitor $\mathrm{C}_{1}$, previously discharged, forces a zero voltage between gate and source of $\mathrm{M}_{10}$. Thus, switch $\mathrm{M}_{10}$ is open disregarding the value of $\mathrm{V}_{\mathrm{i}}$. During this phase, capacitor $\mathrm{C}_{2}$ is discharged and the output of inverters $\mathrm{I}_{3}$ and $\mathrm{I}_{4}$ is neglected.

Similarly to what happens with transistor $\mathrm{M}_{1}$ of the rectifier (Fig. 8), a sub-circuit is included to bias the bulk of $\mathrm{M}_{10}$ and prevent latch-up.

\section{Simulations}

The power management module is simulated to check the performance. While receiving or transmitting a bitstream, the sensor is assumed in low power mode, with a maximum current consumption of about $350 \mu \mathrm{A}$; while performing a measurement, the sensor is assumed in high power mode, with a maximum current consumption of about $1.3 \mathrm{~mA}$. These power consumptions are much higher than those previously reported. However, a worst scenario is assumed to check the capability of the power module to operate with more power-demanding sensors. In this set of simulations the power delivered from the receiving inductor to a matched load is equal to $5 \mathrm{~mW}$. This value decreases while downlink communication is performed. While transmitting a high logic value the transferred power is about $3 \mathrm{~mW}$; while transmitting a low logic value the transferred power is about $1 \mathrm{~mW}$. These values have been measured with the external patch described in Section III within a distance of $10 \mathrm{~mm}$ between the inductors.

A purely capacitive matching network $\left(\mathrm{C}_{\mathrm{A}}\right.$ and $\mathrm{C}_{\mathrm{B}}$ in Fig. 7) is used between the receiving inductor and the input of the rectifier to have impedance matching. Due to the non-linearity of the rectifier, it is not possible to define a linear input impedance for that block. Thus, simulations have been performed to determine an average value for the input impedance of the rectifier. With the data just introduced, the average input impedance of the rectifier is about $150 \Omega$. This value is used to select capacitors $\mathrm{C}_{\mathrm{A}}$ and $\mathrm{C}_{\mathrm{B}}$ of the matching network.

By considering the dropout voltage of the regulator equal to $300 \mathrm{mV}$, the output voltage $\mathrm{V}_{\mathrm{o}}$ of the rectifier should always be higher than $2.1 \mathrm{~V}$ to assure the correct functioning of the sensor at $1.8 \mathrm{~V}$. A simulation is performed to check the behavior of the rectifier and the amplitude demodulator (Fig. 11).

Capacitor $\mathrm{C}_{\mathrm{o}}$ is charged until it reaches a voltage of $2.75 \mathrm{~V}$ at time $270 \mu \mathrm{s}$. Eighteen bits, with a bit-rate of $100 \mathrm{kbps}$, are sent to the sensor by modulating the signal $\mathrm{V}_{\mathrm{i}}$ at time $300 \mu \mathrm{s}$. Those bits are correctly detected at the output $\mathrm{V}_{\text {dem }}$ of the demodulator at every rising edge of the clock signal $\varphi_{1}$. During the communication, the output voltage $\mathrm{V}_{\mathrm{o}}$ of the rectifier never goes below $2.1 \mathrm{~V}$. An uplink communication is simulated at time $520 \mu \mathrm{s}$. Several bits are sent with a bit-rate of $100 \mathrm{kbps}$ from the sensor to the external patch by shortcircuiting the input of the rectifier, according to signal $V_{\text {up }}$ of Fig. 8. The effect of such modulation on the input voltage $\mathrm{V}_{\mathrm{i}}$ is reported in Fig. 11. Similarly to what reported for the downlink communication, the output voltage $\mathrm{V}_{\mathrm{o}}$ of the rectifier never goes below $2.1 \mathrm{~V}$ during the transmission.

\section{Conclusions}

A power delivery system for implantable sensors is presented. Power delivery and power management modules are reported, together with a description of the implantable sensor to be powered.

An external delivery device, embedded into a skin patch, is able to transmit up to $15 \mathrm{~mW}$ through inductive link, within a distance of $6 \mathrm{~mm}$ between the transmitting and the receiving inductors. Downlink communication is performed at $100 \mathrm{kbps}$ with ASK modulation; uplink communication is performed at $66 \mathrm{kbps}$ with LSK modulation. Long range communication with a remote device is enabled by a bluetooth module embedded into the patch.

The power management module, including voltage rectifier, amplitude demodulator, and load modulator is presented and discussed by means of simulations. The design has been fabricated in $0.18 \mu \mathrm{m}$ CMOS technology. Future works will involve the circuit characterization by means of measurements. 


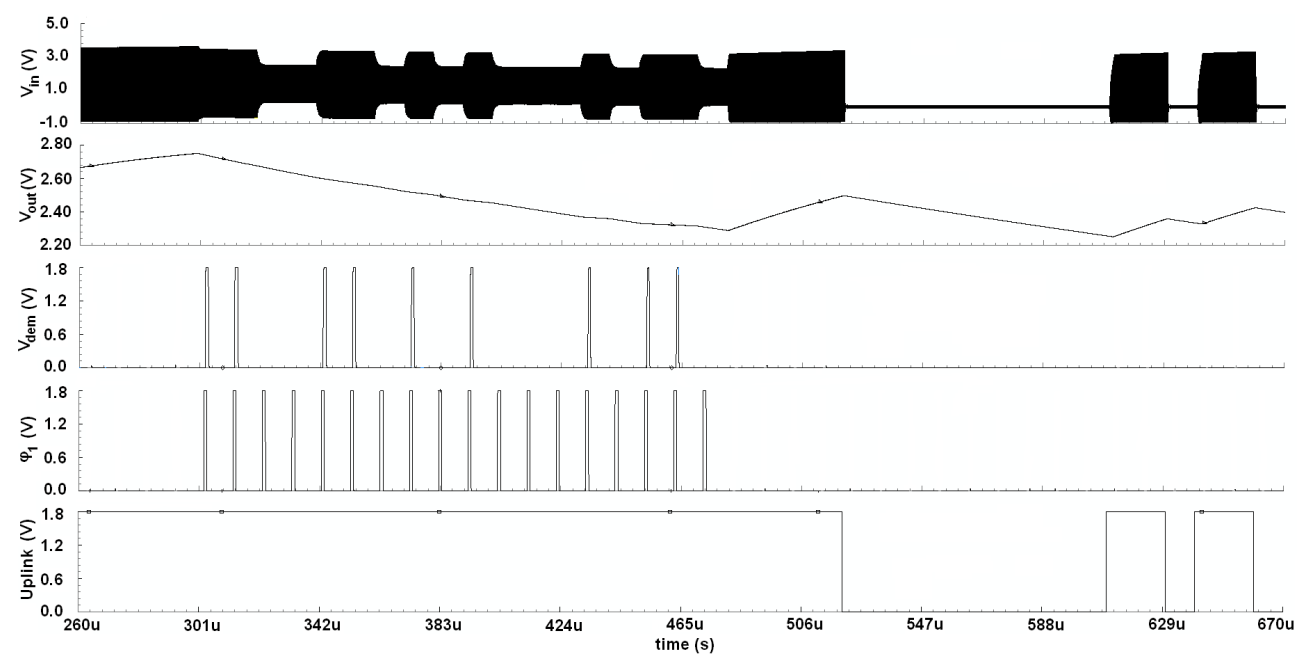

Fig. 11. The power module is simulated to check the performance. Downlink and uplink communications are correctly performed at $100 \mathrm{kbps}$. The output of the rectifier is always higher than $2.1 \mathrm{~V}$; thus, the regulator can provide a stable supply voltage of $1.8 \mathrm{~V}$ to the sensor.

\section{ACKNOWLEDGEMENT}

The authors would like to thank Ms. Irene Taurino (from LSI-EPFL) for the help in measuring the lactate and Prof. Linda Thöny-Meyer (from EMPA) for providing the probe protein. A special thanks to Ms. Gözen Köklü (from LSI-EPFL) for the precious suggestions on circuit design.

\section{REFERENCES}

[1] F. Valgimigli, F. Lucarelli, C. Scuffi, S. Morandi, and I. Sposato, "Evaluating the Clinical Accuracy of GlucoMen Day: A Novel Microdialysisbased Continuous Glucose Monitor," J Diabetes Sci Technol., vol. 4, p. $11821192,2010$.

[2] A. Poscia, D. Messeri, D. Moscone, F. Ricci, and F. Valgimigli, "A Novel Continuous Subcutaneous Lactate Monitoring System," Biosens Bioelectron, vol. 20, pp. 2244 - 2250, 2005.

[3] G. De Micheli, S. Ghoreishizadeh, C. Boero, F. Valgimigli, and S. Carrara, "An Integrated Platform for Advanced Diagnostics," in IEEE DATE Conf., 2011, pp. 1-6.

[4] S. Carrara, S. Ghoreishizadeh, J. Olivo, I. Taurino, C. Baj-Rossi, A. Cavallini, M. Op de Beeck, C. Dehollain, W. Burleson, F. Moussy, A. Guiseppi-Elie, and G. De Micheli, "Fully Integrated Biochip Platforms for Advanced Healthcare," Sensors, vol. 12, pp. 11013-11060, 2012.

[5] A. Du Pasquier, I. Plitz, S. Menocal, and G. Amatucci, "A Comparative Study of Li-ion Battery, Supercapacitor and Nonaqueous Asymmetric Hybrid Devices for Automotive Applications," J. Power Sources, vol. 115 , no. 1, pp. 171-178, Mar. 2003.

[6] Thinergy micro-energy cells (mecs). [Online]. Available: http://www. infinitepowersolutions.com

[7] J. Olivo, S. Carrara, and G. De Micheli, "Energy Harvesting and Remote Powering for Implantable Biosensors," IEEE Sens. J., vol. 11, no. 7, pp. $1573-1586,2010$

[8] T. Akin, K. Najafi, and R. Bradley, "A Wireless Implantable Multichannel Digital Neural Recording System for a Micromachined Sieve Electrode," IEEE J. Solid-St. Circ., vol. 33, pp. 109 -118, 1998.

[9] C. Sauer, M. Stanaćević, G. Cauwenberghs, and N. Thakor, "Power Harvesting and Telemetry in CMOS for Implanted Devices," IEEE Trans. Circuits Syst. I, Reg. Papers, vol. 52, pp. 2605 - 2613, 2005.

[10] B. Lenaerts and R. Puers, "An Inductive Power Link for a Wireless Endoscope," Biosens Bioelectron, vol. 22, pp. 1390 - 1395, 2007.

[11] K. Silay, D. Dondi, L. Larcher, M. Declercq, L. Benini, Y. Leblebici, and C. Dehollain, "Load Optimization of an Inductive Power Link for Remote Powering of Biomedical Implants," in IEEE ISCAS Conf., 2009, pp. $533-536$

[12] M. Catrysse, B. Hermans, and R. Puers, "An Inductive Power System with Integrated Bi-directional Data-transmission," Sensor Actuat A-Phys, vol. 115 , pp. $221-229,2004$.
[13] J. Parramon, P. Doguet, D. Marin, M. Verleyssen, R. Muñoz, L. Leija, and E. Valderrama, "ASIC-Based Batteryless Implantable Telemetry Microsystem for Recording Purposes," IEEE EMBC, vol. 5, pp. 2225 $-2228,1997$.

[14] G. Gudnason, E. Bruun, and M. Haugland, "A Chip for an Implantable Neural Stimulator," Analog Integr. Circuits Signal Process., vol. 22, pp. $81-89,2000$.

[15] B. Smith, Z. Tang, M. Johnson, S. Pourmehdi, M. Gazdik, J. Buckett, and P. Peckham, "An Externally Powered, Multichannel, Implantable Stimulator-telemeter for Control of Paralyzed Muscle," IEEE Trans Biomed Eng, vol. 45, pp. $463-475,1998$.

[16] M. Ahmadi and G. Jullien, "A Wireless-implantable Microsystem for Continuous Blood Glucose Monitoring," IEEE Trans. Biomed. Circuits Syst., vol. 3, pp. $169-180,2009$.

[17] S. O'Driscoll, A. Poon, and T. Meng, "A mm-sized Implantable Power Receiver with Adaptative Link Compensation," in ISSCC - Digest of Technical Papers, 2009, pp. 294-295, 295a.

[18] Activa RC Recharging System 37751. Medtronic.

[19] I. Taurino, R. Reiss, M. Ritcher, M. Fairhead, L. Thony-Meyer, G. De Micheli, and S. Carrara, "Comparative Study of Three Lactate Oxidases from Aerococcus Viridans for Biosensing Applications," Electrochim Acta, in Press.

[20] S. Carrara, V. Shumyantseva, A. Archakov, and B. Samorì, "ScreenPrinted Electrodes Based on Carbon Nanotubes and Cytochrome P450scc for Highly Sensitive Cholesterol Biosensors," Biosens Bioelectron, vol. 24, pp. 148-150, 2008.

[21] C. Boero, J. Olivo, S. Carrara, and G. De Micheli, "New Approaches for Carbon Nanotubes-Based Biosensors and their Application to Cell Culture Monitoring," IEEE Trans. Biomed. Circuits Syst., in Press.

[22] H. Banba, H. Shiga, A. Umezawa, T. Miyaba, T. Tanzawa, S. Atsumi, and K. Sakui, "A CMOS Bandgap Reference Circuit with Sub-1-V Operation," IEEE J. Solid-St. Circ., vol. 34, pp. 670-674, 1999.

[23] S. Ghoreishizadeh, I. Taurino, S. Carrara, and G. De Micheli, "A Current-Mode Potentiostat for Multi-Target Detection Tested with Different Lactate Biosensors," in IEEE BioCAS Conf., 2012, accepted.

[24] J. Olivo, S. Carrara, and G. De Micheli, "IronIC Patch: A Wearable Device for the Remote Powering and Connectivity of Implantable Systems," in IEEE I2MTC Conf., 2012, pp. 286 - 289.

[25] B. Lenaerts and R. Puers, Omnidirectional Inductive Powering for Biomedical Implants. Springer, 2009.

[26] N. Sokal, "Class-E RF Power Amplifiers," $Q E X$, pp. 9-20, Jan./Feb. 2001.

[27] F. Raab, "Idealized Operation of the Class-E Tuned Power Amplifier," IEEE T. Circuits. Syst., vol. CAS-24, pp. 725-735, 1977.

[28] J. Olivo, S. Carrara, and G. De Micheli, "A Study of Multi-Layer Spiral Inductors for Remote Powering of Implantable Sensors," IEEE Trans. Biomed. Circuits Syst., in Press. 